\title{
SHOULD WE CONFINE THE CARDIO HEPATIC SYNDROME ONLY IN CONGESTIVE CARDIAC FAILURE PATIENTS?
}

\author{
B. Rajendra, B. Sukanya, Nayana Joshi
}

\begin{abstract}
:
Introduction: Liver function abnormalities are not uncommon in patients with heart failure. Multiple reasons have been cited like impaired perfusion or elevated right-sided cardiac pressures, or are secondary to drug toxicity. In this study, we analyzed the patients admitted at our center to detect the profile of cardio-hepatic syndrome. This analysis may explore new etiologies for cardio-hepatic syndrome.

Materials And Methods: This is an observational retrospective study done at our institute. We collected the liver function tests which were conducted in patients admitted in cardiology in 2015 (Jan to Dec at our_center. Patients having abnormal liver function tests were analyzed for various etiologies. SGPT value $>45$ Units per liter is considered as elevated.

Results: Out of the patients admitted to cardiology department, SGPT and SGOT values are available in 2803 and 4577 patients respectively. Mean age of these patients was $58 \pm 12.9$ yrs.

In SGPT group 1881 were males. In 432(15.4\%) patients SGPT was elevated. In them 326 (76\%) were males. Among the patients in whom SGPT is elevated, also had elevated CPK and CPK-MB due to $\mathrm{MI}$ were in 154 patients (35.6\%). In 24 patients $(5.6 \%)$ SGPT was elevated along with NT pro BNP levels. Rest of the SGPT elevated patients (254-58.8\%) does not come under CCF or MI category and out these patients about 146 patients were on either on statin or other drugs which can increase the liver enzymes. Still we require to evaluate the cause of hepatic abnormality in 106(24.5\%) patients admitted with cardiac disease.

Conclusions: Cardio-hepatic syndrome is not just confined to heart failure. Though heart failure, MI and drug induced hepatic dysfunction accounted for $75.5 \%$ of the etiology, we require to see present unknown the etiology for this sub group of cardio hepatic syndrome. Further elucidating the etiology for the remaining $24.5 \%$ cardio hepatic syndrome is of much interest.
\end{abstract}

Article received on 01 JAN 2017, published on 31JAN 2017.

B.Rajendra ${ }^{1}$, B. Sukanya ${ }^{2}$, Nayana Joshi ${ }^{3}$

${ }^{1}$ Senior Resident, Department of Cardiology, NIMS, India

${ }^{2}$ Assoc. Professor, Department of Medical Gastroenterology, NIMS.

${ }^{3}$ Addl. Professor, Department of Medical Gastroenterology, NIMS.

Corresponding author: B.Rajendra,

Email: dr.b.rajendra@gmail.com
Keywords: Cardio-hepatic syndrome, heart failure, hepatic dysfunction, liver function tests, cardiac enzymes.

\section{INTRODUCTION:}

Heart failure (HF) is a major public health problem, with frequent hospitalizations, impaired quality of life, and shortened life expectancy [1]. As HF advances, it is often characterized by an increasing inability to meet the metabolic requirements of end organs or skeletal muscle. While much attention has been directed toward the intersection of HF and renal function, the impact of HF on hepatic function has been poorly described.

Similar to the now widely described "Cardiorenal" syndromes, more attention is needed in describing "Cardio-hepatic" interactions. Over the last several years, a number of studies have described poor outcomes associated with the development of cardio renal syndromes, as well as potential solutions to mitigate further renal injury while treating HF [2]. In contrast, much less is known about impaired liver function in patients with HF.

Abnormalities in liver function tests (LFTs) are not an uncommon finding in patients with HF. These abnormalities are a result of impaired perfusion or elevated right-sided cardiac pressures, or are secondary to drug toxicity. Attempts at describing the features of chronic liver damage secondary to HF have been ongoing since the early 20th century [3,4]. Nevertheless, neither the pathophysiologic basis underlying these findings nor the clinical impact of impaired liver function on HF outcomes has been clearly delineated.

The aim of this study is to correlate liver function tests and different clinico-etiological profiles in patients admitted in ICCU with acute congestive heart failure.

\section{MATERIAL AND METHODS:}

All cases admitted in our institute ICCU for coronary artery disease or heart failure without history of primary liver pathology were included in the study. Liver function tests (LFT), cardiac enzymes and NT pro BNP 
of all these patients (study period was 2015 Jan to Dec 2015) were analysed. LFT includes SGPT, SGOT and total bilirubin. Abnormal liver function tests were defined as values above the upper limit of normal (normal values-SGPT $<45 \mathrm{IU} / \mathrm{L}$, SGOT $<40 \mathrm{IU} / \mathrm{L}$ ). To account for confounding by drug-induced liver injury, we collected the data of medication use of all patients. To know the severity of heart failure contributing to increase of liver enzymes, we collected the data of NT pro BNP levels (NT pro BNP-BNP <200pg/L).In acute coronary syndrome patients, cardiac enzymes levels were noted (CPK $<200 \mathrm{IU} / \mathrm{L}, \mathrm{CPKMB}<25 \mathrm{IU} / \mathrm{L})$.

\section{RESULTS:}

Total number of patients included in the study are 15178 , of which 10096(66.5) are males and 5082(33.5\%) are females. Average age of the study group is $58.2 \mathrm{yrs}$. (males 59 yrs, female 56.8yrs) (Table 1, Fig 1).

Table 1: Total no of cases analyzed.

\begin{tabular}{|l|l|l|}
\hline Variables & Number & Mean age(yrs) \\
\hline Males & $10096(66.5)$ & 59.0 \\
\hline Females & $5082(33.5)$ & 56.8 \\
\hline Total & 15178 & 58.2 \\
\hline
\end{tabular}

Fig 1: Demographic features of study population.

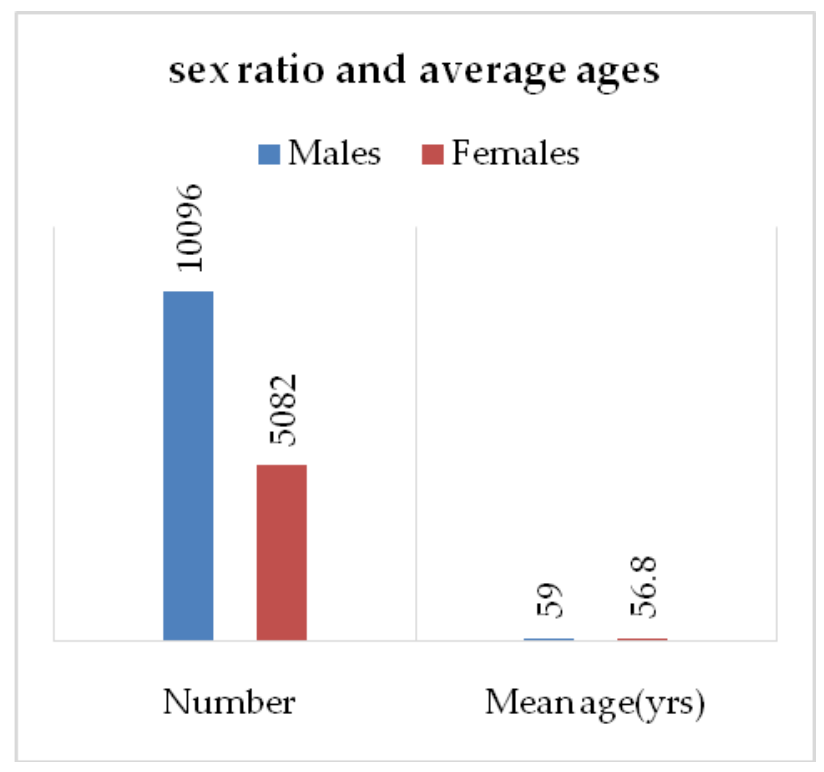

Below dot plot diagram (Fig 2) is showing the distribution of study population in different age groups. Maximum numbers of patients were in $6^{\text {th }}$ or $7^{\text {th }}$ decade.

Fig 2: Distribution of study population in different age groups.

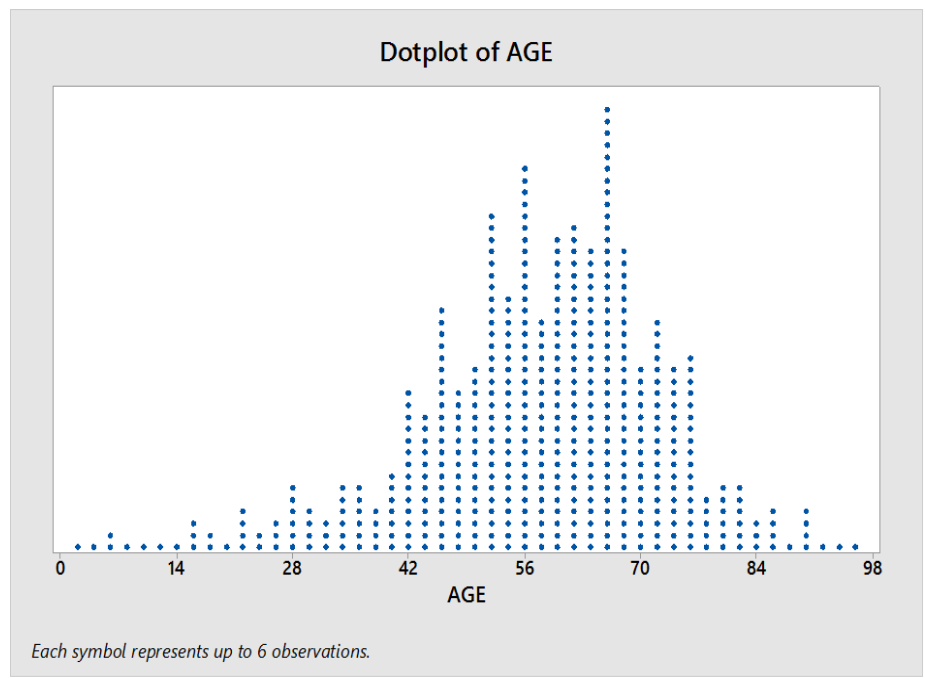

Liver function test analysis: Among the patients LFT, SGOT levels were available in 4576 patients which includes $64.5 \%$ males and $35.5 \%$ females (Fig 3). SGPT levels were available in 2803 patients of which $67 \%$ are males and $33 \%$ are females.

Fig 3: Liver function profile in ICCU admitted patients.

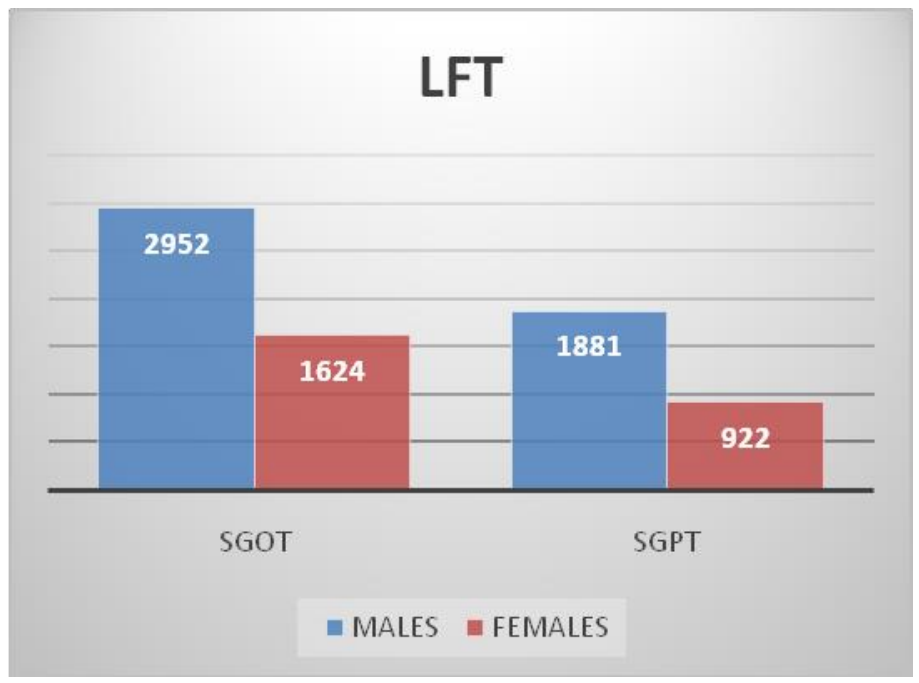

In Table 2 details of patients with liver function abnormalities were given. Among the patients admitted in ICCU elevated SGPT levels are seen in 432 patients of whom $76 \%$ are males and $24 \%$ are females (Fig 4 ). The 
cutoff value for SGPT levels $>45 \mathrm{u} / \mathrm{L}$ is considered as elevated.

Table 2: Patients with Liver function abnormalities.

\begin{tabular}{|l|l|l|l|}
\hline Liver function tests & Male & Female & Total \\
\hline SGPT & $329(76.1 \%)$ & $103(23.9 \%)$ & 432 \\
\hline SGOT & $524(68.8 \%)$ & $237(31.2 \%)$ & 761 \\
\hline
\end{tabular}

Fig 4: Sex distribution in patients with elevated SGPT values.

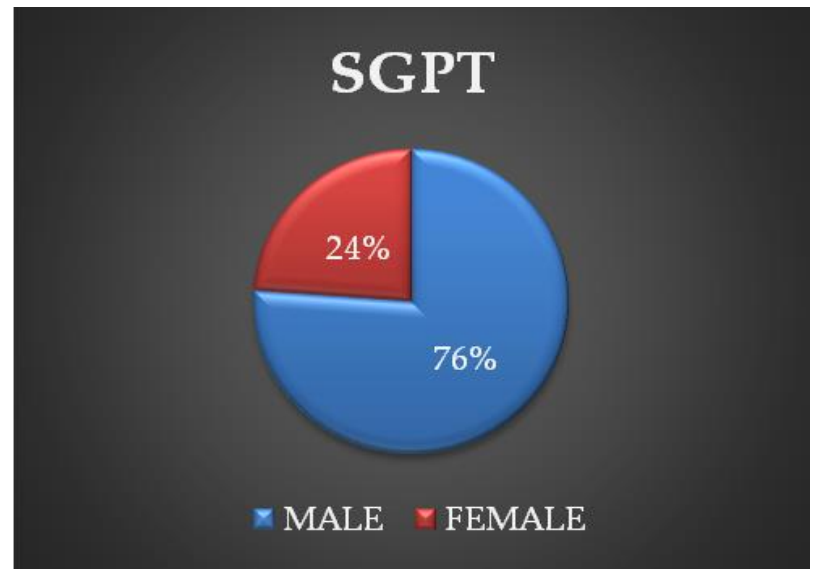

Cardiac enzymes analysis: in table 3 and fig 6, available data of cardiac enzymes and NT pro-BNP levels in the study population were given.

Table 3: Cardiac enzymes and NT pro-BNP levels available patient data.

\begin{tabular}{|l|l|l|l|}
\hline Variables & CPK & CPK-MB & NTpro-BNP \\
\hline Males & $2624(66.5)$ & $2749(83.8)$ & $936(72.6)$ \\
\hline Females & $1321(33.5)$ & $1132(26.2)$ & $353(27.4)$ \\
\hline Total & 3945 & 3281 & 1289 \\
\hline
\end{tabular}

Fig 6: Bar diagram demonstrating the Cardiac enzymes and NT pro-BNP levels available patients data.

\section{CARDIAC ENZYMES}

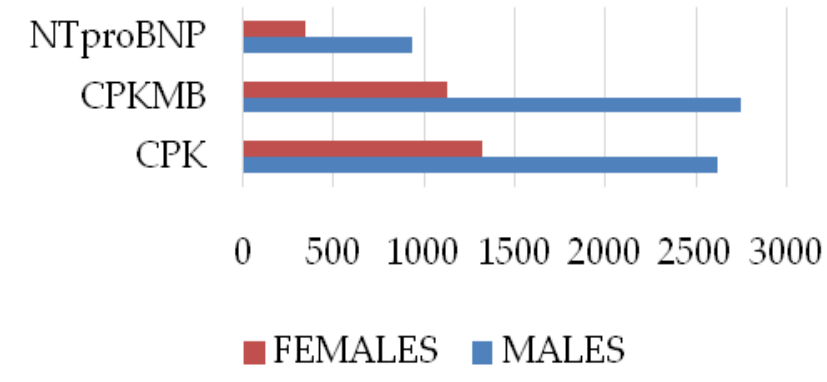

CPK levels were done among 3945 patients $66.5 \%$ of them are males and $33.5 \%$ are females. CPK-MB levels are done in 3281 patients of which $84 \%$ are males and $26 \%$ are females. NT pro-BNP levels are done among 1289 patients of that $72.6 \%$ are males and $27.4 \%$ are females

Abnormally elevated levels cardiac enzymes and NT pro-BNP level patients details were given in Table 4.

Table 4: Elevated cardiac enzymes in study population.

\begin{tabular}{|l|l|l|l|}
\hline $\begin{array}{l}\text { Parameters (No } \\
\text { of pts and \%) }\end{array}$ & CPK & CPKMB & $\begin{array}{l}\text { NT pro- } \\
\text { BNP }\end{array}$ \\
\hline Males & $57(69.5 \%)$ & $2117(65.4 \%)$ & $299(68.7 \%)$ \\
\hline Females & $25(30.5 \%)$ & $1116(34.6 \%)$ & $160(31.3 \%)$ \\
\hline Total No & 82 & 3233 & 459 \\
\hline
\end{tabular}

The upper normal limit (UNL) for CPK is taken as $200 \mathrm{mcg} / \mathrm{land}$ the patients with elevated CPK levels are 82 out of which $69.5 \%$ are males and $30.5 \%$ are females. The UNL for CPK-MB is taken as $25 \mathrm{IU} / \mathrm{L}$ and the patients with elevated levels of CPKMB are 3233 of which $65.4 \%$ are males and $34.6 \%$ are females. The UNL for NT pro BNP is taken as $200 \mathrm{pg} / \mathrm{ml}$ and the patients with elevated levels are 459 out of which $68.7 \%$ are males and $31.3 \%$ are females (Fig 7).

Fig 7 Distribution of elevated cardiac enzymes in males and females

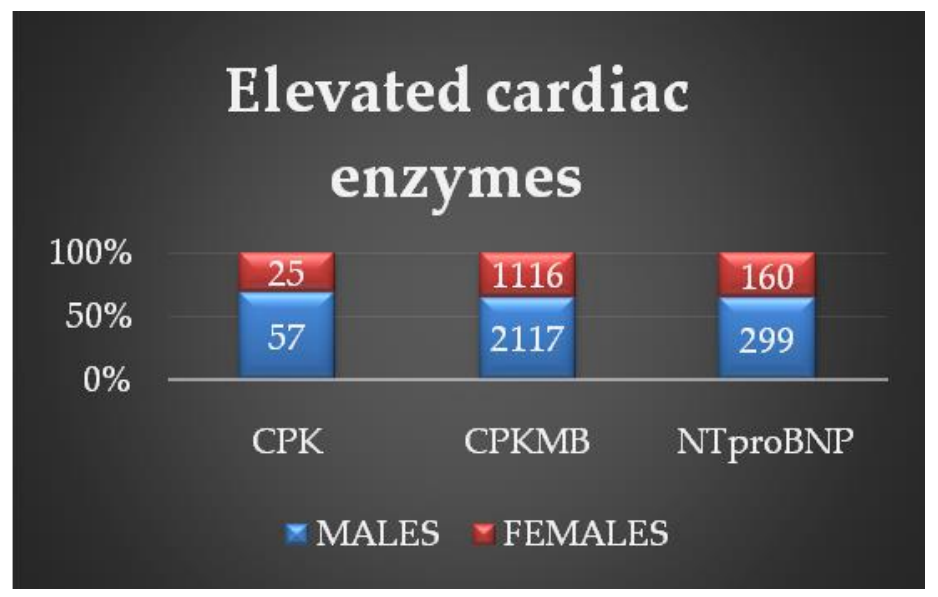

In Table 5 different causes for elevation of SGPT were mentioned. As SGPT is the earliest liver enzyme to rise during acute cardiac failure in our study we have compared SGPT levels in patients admitted in ICCU 
either with AMI/CHF. In some patients without either elevated CPK or NT pro BNP levels it is found that they are on drugs which have potential to cause liver damage. Out the of 324 patients with elevated SGPT, $47.5 \%$ of patients it was due to acute myocardial infarction (AMI), $7.4 \%$ of cases due to congestive heart failure $(\mathrm{CHF})$ and remaining $45.1 \%$ of cases were due to drugs (Fig 8).

Table 5: Different causes for the elevation of SGPT.

\begin{tabular}{|l|l|l|l|}
\hline Parameters & AMI & CHF & DRUGS \\
\hline Total & 154 & 24 & 146 \\
\hline Male & $98(63.6)$ & $17(70.8)$ & $92(63.0)$ \\
\hline Female & $56(36.4)$ & $07(29.2)$ & $54(37.0)$ \\
\hline
\end{tabular}

Fig 8: Bar diagrammatic representation of sex distribution in the different cause for elevated SGPT.

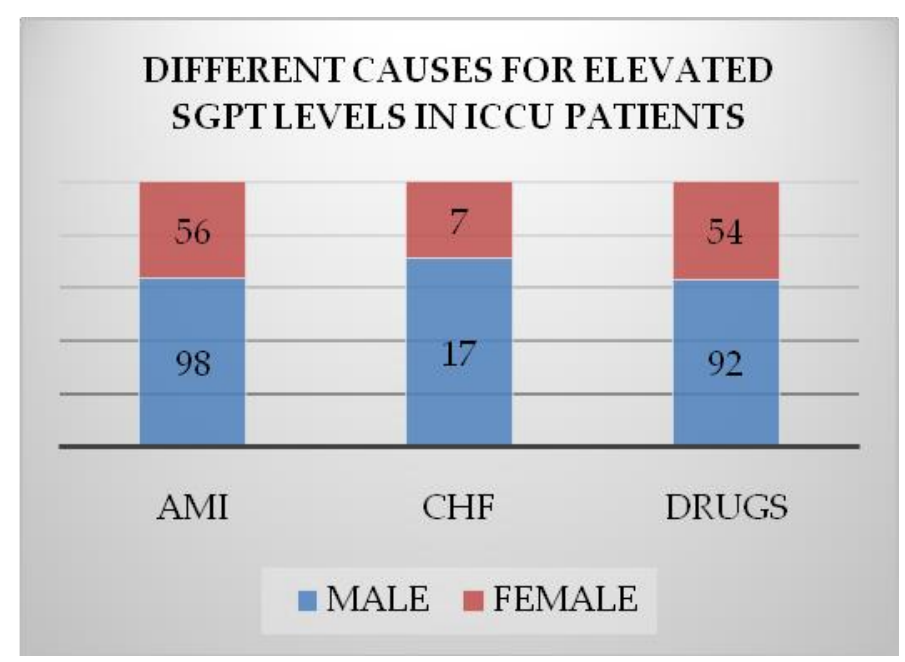

\section{DISCUSSION}

Recent publications have shown that liver function test (LFT) abnormalities were associated with AHF severity. Clinical signs of systemic congestion were found to be associated with cholestasis, when signs of hypoperfusion were associated with liver cytolysis. Defining the LFT profile in AHF may play an important role in the future management of AHF patients [5]. In our study, we have analyzed SGPT levels of patients admitted in ICCU, as it is considered gold standard enzymatic marker for liver injury. SGPT values were available in 2803 patients, of whom $67 \%$ are males and
$33 \%$ are females. Out of them 432 patients have elevated SGPT levels (i.e. $15 \%$ of the patients) of whom $76.1 \%$ are males and $23.9 \%$ are females. The prevalence is similar to the study done by Lau et al[6].

The common cause of cardio hepatic syndrome is acute or decompensated chronic heart failure according to Villeval'de SV et al, the incidence of concurrent AKI and CHS in patients with decompensated HF is $20.1 \%$. Concurrent kidney and liver dysfunctions is associated with more obvious signs of hypo-perfusion and congestion and characterized by worse prognosis [7]. In our study, among the patients with elevated SGPT levels, 154 patients presented with Acute MI as indicated by the elevated CPK/CPKMB levels, 24 patients presented with acute decompensated $\mathrm{CHF}$ as indicated by the elevated NT pro-BNP levels and 146 patients found to have been taking hepatotoxic drugs (statins).

In all previous studies, the different causes for CHS syndrome mentioned were myocardial infarction, atrial fibrillation, chronic kidney disease and acute or decompensated chronic heart failure. In our study, we have found that AMI, CHF, drugs constitute only $75 \%$ (324) of patients with hepatic dysfunction and the etiology for the remaining $25 \%$ of the patients need to be evaluated.

This subset of $25 \%$ of patients requires evaluation to know the cause. We are proposing that probably systemic vasoconstriction due to cardiac alignment may produce the liver injury and in turn causing the increase in liver enzymatic levels.

\section{CONCLUSIONS:}

Cardio hepatic syndrome is not just confined to heart failure. Though heart failure, MI and drug induced hepatic dysfunction accounted for $75 \%$ of the etiology, we require seeing present unknown the etiology for this subgroup of cardio hepatic syndrome. Further elucidating the remaining $24 \%$ cardio hepatic syndrome is of much interest.

\section{REFERENCES:}

1. Hunt SA, Abraham WT, Chin MH, et al. ACC/AHA 2005 guideline update for the diagnosis and management of chronic heart failure in the adultd summary article. A report of the American College of 
Cardiology/American Heart Association Task Force on Practice Guidelines (Writing Committee to Update the 2001 Guidelines for the Evaluation and Management of Heart Failure). J Am Coll Cardiol 2005;46:1116-43.

2. Smith GL, Lichtman JH, Bracken MB, et al. Renal impairment and outcomes in heart failure: systematic review and meta-analysis. J Am Coll Cardiol 2006;47:1987-96.

3. Boland EW, Willius FA. Changes in the liver produced by chronic passive congestion: with special reference to the problem of cardiac cirrhosis. Arch Intern Med 1938;62:723-39.

4. Sherlock S. The liver in heart failure; relation of anatomical, functional, and circulatory changes. Br Heart J 1951;13:273-93.
5. Laribi S, MebazaaA Cardio hepatic syndrome: liver injury in decompensated heart failure. Curr Heart Fail Rep. 2014 Sep;11(3):236-40.

6. Lau, G.T., Tan, H.C., and Kritharides, L. Type of liver dysfunction in heart failure and its relation to the severity of tricuspid regurgitation. Am J Cardiol. 2002; 90: 1405-1409.

7. Villeval'de SV, KobalavaZhD, Solov'eva AE, Moiseev VS. The concurrence of kidney and liver dysfunctions in decompensated heart failure. TerArkh, 2016;88(6):40-4. 